\title{
PENTINGNYA KETERAMPILAN DIGITAL LITERASI BAGI PUSTAKAWAN
}

\author{
P. Iman Hery Wahyudi*
}

Pengutipan: Wahyudi, P. I. H. (2017). Pentingnya keterampilan digital literasi bagi pustakawan. Khizanah al-Hikmah : Jurnal Ilmu Perpustakaan, Informasi, dan Kearsipan. 5(2), 187-195.

DOI: https:// doi.org/10.24252/kah.v5i2a6

\section{*Pustakawan Universitas Pelita Harapan \\ imanhery@gmail.com}

\begin{abstract}
ABSTRAK
Perkembangan teknologi informasi membuat arus informasi sangat mudah diakses tanpa batas ruang dan waktu. Tidak semua informasi sahih sebagai bahan acuan. Dalam era digital, seorang pustakawan harus memiliki keterampilan digital literasi supaya dapat menelusur dan mengidentifikasikan sumber informasi yang valid. Ada 2 komponen penting digital literasi, yaitu strategi penelusuran (kata kunci, indeks online, boolean logic dan sintaks) dan evaluasi web (authoritatif, akurasi, obyektifitas, kekinian, cakupan serta gaya bahasa). Komponen tersebut perlu diketahui oleh pustakawan, agar ia menyajikan sumber-sumber informasi secara valid, reliable dan akurat sesuai kebutuhan pemustaka
\end{abstract}

Kata kunci: Digital literasi, strategi penelusuran, evaluasi web

\section{ABSTRACT}

The development of information technology made the information flow is very easily accessible without limits of space and time. Not all information was valid as a reference material. In the digital era, the librarian must have digital literacy skills in order to access and identify valid sources of information. There were two essential components of digital literacy, i.e. the search strategy (key word, online index, boolean logic, and syntax) and the evaluation of the web (authoritative information, accuracy, objectifies, immediacy, scope and style of language). These components needed to be known by the librarians, in order to present the information sources were valid, reliable and accurate as required by users'.

Key words: Digital literacy, search strategy, web evaluation

\section{PENDAHULUAN}

Perkembangan teknologi komputer dan telekomunikasi pada dekade tahun 2000-an sangat meningkat, hal ini ditandai dengan tren penggunaan internet, intranet, e-commerce dan sebagainya yang melonjak di berbagai sektor formal dan informal. Penggabungan teknologi antara komputer dengan telekomunikasi ini menghasilkan teknologi informasi yang mampu jauh menembus batas-batas fisik, ruang dan waktu.

Perkembangan teknologi informasi sangat berpengaruh terhadap laju informasi yang kita dapat. Lonjakan laju informasi tersebut memberikan dampak yang sangat nyata dalam berbagai sektor layanan jasa informasi, tak terkecuali perpustakaan. Pengaruh yang dirasakan oleh perpustakaan bisa dikatakan sangat besar, mengapa demikian? Karena 
komoditas utama perpustakaan tak lain adalah data dan informasi.

Derasnya arus informasi dari berbagai sumber elektronik, merupakan tantangan tersendiri bagi pustakawan di era digital seperti saat ini. Pustakawan dituntut bukan hanya piawai dalam hal klerikal melainkan juga harus melek teknologi informasi. Perkembangan teknologi informasi telah membawa perubahan dalam penyediaan sumber-sumber informasi, seiring dengan menurunnya penggunaan bahan kertas (paperless) sebagai media utamanya. Akibatnya laju informasi di dunia maya menjadi tak terelakkan lagi. Banyaknya ketersediaan sumber informasi, tentunya akan menyulitkan pemustaka dalam hal mencari dan mengidentifikasikan informasi mana yang valid, reliable dan akurat untuknya. Tak sedikit pemustaka yang salah dalam mengambil sumber informasi sebagai bahan referensi, akibatnya bukan hanya menyesatkan tetapi juga menihilkan karya yang dihasilkan pemustaka tersebut lantaran salah dalam menelusur dan memanfaatkan sumber informasi.

\section{RUMUSAN MASALAH}

Banyaknya sumber informasi yang tersebar di internet, tidak selalu diikuti dengan kualitas data informasi yang disajikan. Tidak sedikit yang tergolong sebagai sampah informasi. Atas dasar inilah, kita sebagai pustakawan dituntut bukan hanya bisa menggunakan perangkat elektronik namun juga harus memiliki kemampuan memilah dan menyeleksi informasi mana yang valid dan mana yang tidak.

\section{TUJUAN PENELITIAN}

Penelitian ini berusaha untuk memaparkan pentingnya seorang pustakawan memiliki keterampilan dalam digital literasi agar mampu menemukan sumber-sumber informasi yang valid, reliable dan akurat.

\section{KAJIAN PUSTAKA}

\section{a. Digital Literasi}

Digital literasi merupakan bagian dari literasi informasi secara keseluruhan, di dalam IFLA ALP Workshop dalam Sulistyo-Basuki (2013) mendefinisikan digital literasi sebagai kemampuan memahami dan menggunakan informasi dalam berbagai format dari sejumlah besar sumber daya tatkala sumber daya tersebut disajikan melalui komputer. Sejalan dengan IFLA, menurut Gilster (1997) digital literasi sebagai kemampuan memahami dan menggunakan informasi dari berbagai sumber digital.

Tidak semua pemustaka memahami bahwa informasi yang tersedia di web mempunyai kualitas informasi yang valid dan akurat, namun di sisi lain, tidak semua pemustaka juga tahu menggunakan strategi penelusuran yang benar untuk mendapatkan informasi yang valid tersebut.

Digital literasi mencakup 2 pemahaman, yaitu tentang web dan mesin pencari. Pemahaman tentang web tentunya berkaitan dengan indikator apa saja yang perlu diperhatikan pada sebuah web page, agar tidak terjebak dalam web abal-abal. Sedangkan pemahaman tentang mesin pencari, berkaitan dengan strategi penelusuran untuk mendapatkan informasi seperti penggunaan indeks online, sintaks, dan boolean logic.

\section{b. Strategi Penelusuran Internet}

Tidak dipungkiri lagi bahwa internet merupakan salah satu sumber infomasi 
yang dominan yang digunakan saat ini. Banyak informasi tersebar membuat kita merasa diuntungkan oleh beragamnya sumber informasi ini. Tetapi permasalahannya apakah semua informasi terpasang ini sahih? valid? berkualitas?.

Untuk dapat memperoleh informasi yang sahih, valid dan berkualitas tentu kita harus tahu strategi penelusuran. Menurut Purwono (2008) "strategi penelusuran adalah penelusuran yang dilakukan secara systematic searching, yang meliputi cara-cara bagaimana menggunakan kata kunci, menggunakan boolean logic serta fasilitas-fasilitas penelususran lain yang tersedia pada masing-masing search engine".

Setidaknya ada lima faktor diperlukannya strategi penelusuran informasi melalui internet, (1) Karena informasi yang tersedia sangat banyak dan luas; (2) Untuk memperoleh informasi yang relevan; (3) Untuk menghemat waktu pencarian; (4) Untuk mempermudah pencarian informasi; dan (5) Untuk mendapatkan informasi lain yang berkaitan (Purwono, 2008).

\section{c. Evaluasi Web Pages}

Bila mencari satu kata dalam internet, maka akan ditampilkan begitu banyak web pages yang terpasang. Dari sekian banyak yang terpasang, tidak semua mengandung informasi yang berkualitas. Maka perlu untuk mengetahui indikator apa saja web bisa dikatakan sahih dan berkualitas. Ada beberapa kriteria untuk menilai atau mengevaluasi sebuah web, di antaranya (1) Authority; (2) Objectivity; (3) Accuracy; (4) Currency; dan (5) Usability (Kent State University). Sedangkan Dalhousie University, menambahkan kriteria ke enam yaitu (6) Purpose.
Di beberapa institusi perguruan tinggi terutama di luar negeri, memiliki indikator yang berbeda-beda namanya tetapi pada prinsipnya adalah sama, poinpoin apa saja yang perlu diperhatikan dalam mengakses sebuah web page.

\section{HASIL PENELITIAN DAN PEMBAHASAN}

Perkembangan teknologi informasi yang pesat memberikan pengaruh yang sangat nyata dalam mendapatkan sumber informasi. Perpustakaan sebagai tempat penyedia informasi, sudah tentu merasakan perkembangan tersebut. Dengan adanya teknologi informasi, setidaknya bagi perpustakaan ada beberapa manfaat yang didapatkan, pertama pemanfaatan sumber informasi oleh pemustaka menjadi lebih efektif dan efisien. Karena bisa di akses di mana saja tanpa terbatas ruang dan waktu. Kedua, pengurangan penggunaan bahan kertas sebagai media informasi (paperless). Bukan hanya mendukung pengurangan global warming tetapi juga memudahkan perpustakaan dalam mengelola koleksinya. Dan terakhir, dapat memudahkan kerja rumah tangga perpustakaan seperti pengolahan bahan pustaka.

Namun perlu disadari bahwa berkat kemajuan teknologi ini pula, membuat informasi luar biasa banyaknya. Menurut Sudarsono (2006), internet dapat dikatakan sebagai rimba raya informasi tanpa batas, informasi yang tersaji di dalamnya terus bertambah seiring dengan perkembangan zaman. Seorang pustakawan hendaknya mengerti strategi penelusuran dan mampu mengevaluasi web pages yang didapat.

Pengetahuan pustakawan akan kedua hal tersebut sangat perlu, mengapa? karena kita sebagai penyedia jasa 
informasi haruslah jeli menelusur dan memilah informasi mana yang ilmiah dan mana yang tidak. Tidak banyak pemustaka yang tahu, apakah sebuah informasi valid atau tidak, ilmiah atau hoax, dari lembaga terpercaya atau abalabal dan sebagainya. Oleh karenanya tidak jarang pemustaka akan datang ke pustakawan, untuk meminta bantuan dalam mengidentifikasikan sumber informasi tersebut layak digunakan atau tidak. Banyak pemustaka menggunakan bahan referensi dari sumber-sumber yang tidak valid, tidak reliable dan tidak akurat. Bisa dibayangkan bagaimana jadinya bila suatu karya ilmiah didasari oleh sumbersumber yang tidak valid, sudah pasti berdampak bukan hanya bagi pembuatnya tetapi juga pustakawan sebagai individu yang melek informasi.

\section{a. Strategi Penelusuran}

Dalam mengakses sebuah informasi agar sesuai dengan apa yang kita butuhkan, tentunya kita harus tahu terlebih dahulu strategi penelusurannya. Strategi penelusuran di sini meliputi penggunaan kata kunci sebuah dokumen, menggunakan indeks online, logika boolean dan sintaks yang tersedia pada search engine.

Hal yang perlu diperhatikan dalam menentukan kata kunci adalah sinonim dari kata kunci itu sendiri. Atau kita kesulitan dalam mencari sinonim, kita bisa mencarinya dengan menggunakan thesaurus online seperti www.thesaurus.com, www.merriamwebster.com/thesaurus, www.oxforddictionaries.com/thesaurus/.

Sejalan dengan itu, Pendit (2008), yang mengatakan bahwa merumuskan pertanyaan (kata kunci) merupakan salah satu tahap dalam memulai mencari informasi di internet.
Strategi yang kedua adalah penggunaan indeks online. Ada 3 indeks online, mulai dari tingkat dasar sampai lanjutan.

1) Basic search engine, merupakan indeks online berbasis kata yang digunakan untuk menelusuri informasi yang terdapat di dalam berbagai sumber informasi. Jenis indeks online ini menggunakan robot untuk melakukan penelusurannya, contoh yahoo, google.

2) Direktori, indeks online berbasis subyek yang digunakan untuk menelusuri informasi yang terdapat di dalam berbagai sumber informasi. Jenis indeks online ini menggunakan manusia untuk mengindeks informasi sesuai dengan kelompok subyeknya, contoh dmoz, gigablast, entireweb.

3) Meta search engine, indeks online yang melakukan penelusuran dengan menggunakan beberapa search engine lain sehingga dapat memperluas hasil penelusurannya, contoh dogpile, search.com, unabot.

4) Semantic search engine, indeks online yang menggunakan konteks arti kata pencarian sebagai fokus hasil pencariannya. Semantic search engine mengelompokkan hasil penelusurannya sesuai dengan konteks kata kuncinya, contoh duckduckgo, kengine.

Strategi yang ketiga adalah penggunaan boolean logic. Boolean logic pertama kali dikemukan oleh George Boole di dalam buku The Mathematical Analysis of Logic pada tahun 1847. Pengoperasian strategi ini menggunakan operator AND, OR dan NOT, dimana masing - masing operator memiliki fungsi yang berbeda-beda tapi bisa digabungkan lebih dari satu kata. 
AND atau tanda " + " digunakan apabila kita ingin mencari sumber informasi yang mengandung 2 kata atau lebih. Sebagai contoh Pendidikan AND Indonesia, maka hasil penelusurannya adalah semua sumber informasi mengenai pendidikan yang ada di Indonesia.

Gambar 1. Boolean “AND”

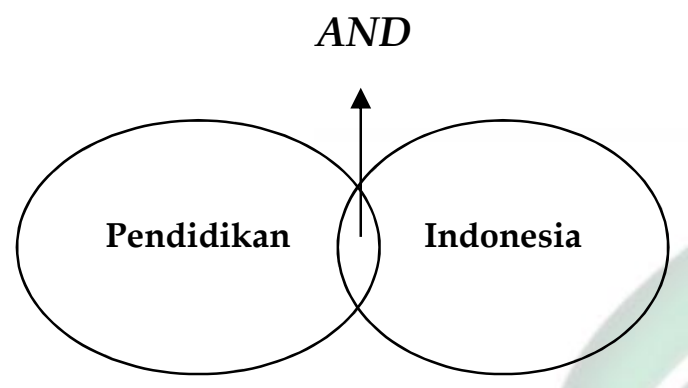

OR atau tanda "|" digunakan apabila kita mencari sumber informasi yang mengandung salah satu dari istilah-istilah yang diperlukan (sinonim). Keuntungan penggunaan kata OR, adalah hasil penelusuran yang kita dapat akan lebih banyak, sebagai contoh remaja OR anak muda, maka yang akan muncul semua informasi mengenai anak muda dan semua informasi mengenai remaja.

Gambar 2. Boolean “OR”

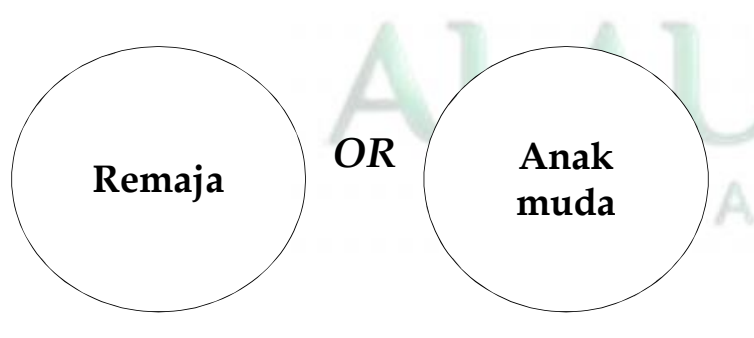

NOT atau tanda "-" digunakan apabila kita ingin menemukan informasi yang mengandung satu kata namun tidak mengandung kata lainnya. Penggunaan NOT untuk membatasi cakupan suatu istilah atau menghindari tercampurnya istilah yang sama yang dipakai oleh disiplin lain. Sebagai contoh pendidikan NOT sekolah dasar, maka hasil penelusuran yang didapat adalah semua sumber informasi tentang pendidikan dari TK sampai SMA kecuali Sekolah Dasar.

Gambar 3. Boolean “NOT”
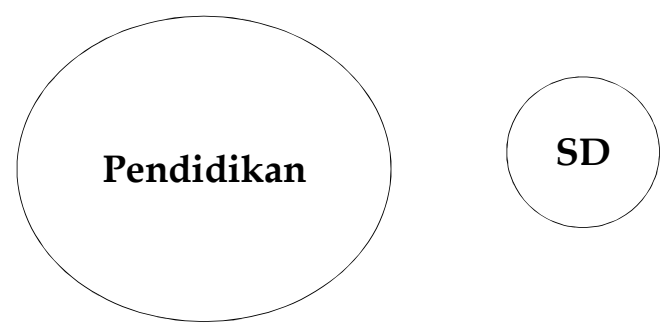

Strategi yang ketiga, adalah penggunaan sintaks yang difasilitasi oleh search engine, seperti

1) Tanda "...", tanda kutip digunakan untuk mencari sumber informasi yang mengandung frasa. Frasa yang diapit akan ditelusuri oleh google menjadi satu kesatuan kata/istilah. Sebagai contoh "digital literasi", maka hasil penelusuran di google adalah semua sumber informasi tentang digital literasi, bukan digital literasi menjadi 2 kata yang terpisah (digital berdiri sendiri, literasi berdiri sendiri).

2) Tanda *, tanda ini digunakan apabila kita tidak tahu penulisan kata yang sebenarnya. Dengan hanya menulis bagian dari suatu kata, kita akan mendapat sumber-sumber informasi yang mengandung kata tersebut dalam berbagai versi. Sebagai contoh child*, maka hasil penelusuran yang didapat adalah semua sumber-sumber informasi yang mengandung kata child seperti children, childhood, childish dan seterusnya.

3) “inurl:". Sintaks ini digunakan apabila kita ingin mencari sebuah informasi dari sumber url tertentu. Sebagai contoh education inurl:.com, maka hasil penelusuran yang didapat semua 
sumber-sumber informasi mengenai pendidikan dengan url.com.

4) “intitle:". Sintaks ini digunakan apabila kita ingin mencari sumber informasi yang judulnya mengandung sebuah kata tertentu. Sebagai contoh intitle: astronomi, maka hasil penelusuran yang didapat adalah semua sumbersumber informasi yang mengandung judul kata astronomi.

5) “intext:". Sintaks ini digunakan apabila kita ingin mencari sumber-sumber informasi yang mengandung teks tertentu. Contoh intext: hoax, maka hasil penelusuran yang didapat adalah semua sumber-sumber informasi yang di dalam kontennya terdapat kata hoax.

6) “site:". Sintaks ini digunakan untuk mencari semua sumber informasi yang berdomain tertentu. Contoh e-learning site:.edu, maka hasil penelusuran yang didapat adalah semua sumber-sumber informasi tentang e-learning dengan domain edu (education).

7) "filetype:". Sintaks ini digunakan untuk mencari semua sumber-sumber informasi yang berformat tertentu. Contoh photosynthesis filetype:.ppt, maka hasil penelusuran yang didapat adalah semua sumber-sumber informasi tentang fotosintesis dengan format powerpoint.

8) "source:". Sintaks ini digunakan untuk menemukan berita atau artikel dari sumber-sumber informasi tertentu. Misalnya pertanian source:kompas.com, maka hasil penelusurannya adalah semua artikel atau berita tentang pertanian yang berasal dari Kompas.com.
9) "location:". Sintaks ini digunakan untuk menemukan artikel-artikel dari sumber-sumber informasi dari lokasi tertetntu. Misalnya perpustakaan location: Indonesia, maka hasil penelusurannya yang didapat adalah semua informasi tentang perpustakaan yang berasal dari Indonesia.

10) "author:". Sintaks ini digunakan untuk mendapatkan sumber informasi dari pengarang tertentu saja. Sebagai contoh perpustakaan author: SulistyoBasuki, maka hasil penelusuran yang didapat adalah semua artikel tentang perpustakaan yang di tulis oleh bapak Prof. Sulistyo Basuki.

11) "info:". Sintaks ini digunakan untuk menemukan semua informasi tentang homepage yang kita inginkan. Sebagai contoh info:www.idionline.org, maka hasil dari penelusuran ini adalah semua informasi yang berkenaan dengan web IDI online.

12) "related:". Sintaks ini digunakan untuk mendaftar web pages yang sama atau yang berhubungan dengan URL yang kita cari. Misalnya related:www.kompas.com, maka hasil dari penelusurannya adalah menampilkan semua web yang sama atau berhubungan dengan web kompas.

\section{b. Evaluasi Web}

Menurut Kent State University ada beberapa indikator yang perlu diperhatikan oleh pustakawan di dalam menilai sebuah konten sumber informasi, di antaranya:

1) Autoritatif

Menurut Baskoro (2010), dalam autoritatif yang perlu diperhatikan adalah; 
a) URL (Uniform Resource Locator) dari sumber informasi tersebut. Apa saja yang diperhatikan dalam URL yaitu cek dokumen URL, apakah dari sebuah institusi atau organisasi atau komersial? dan di mana diterbitkan.

b) Apa yang perlu di cek dari autoritatif ini, yaitu

(1) Pengarang. Apakah penulis memiliki kompeten atau kualifikasi di dalam menulis bidang tertentu.

(2) Adakah sponsor. Bila ada, perlu diperhatikan secara mendalam isi sebuah informasi, karena bisa saja lebih bersifat subyektif, semua tergantung sponsor yang mendanai tulisan di dalam informasi tersebut.

(3) Sitasi dalam dokumen tersebut sudah benar di dalam menyajikannya atau di dalam penulisan daftar rujukan / bibliografi.

\section{2) Akurasi}

Akurasi suatu informasi E selalu dikaitkan dengan orang yang menulis informasi tersebut (Cooke, 2001). Penjelasan mengenai akurasi di halaman web sendiri tercantum dalam about us, profile atau contact us. Penilaian keakurasi-an mencakup;

a) Segi informasinya itu sendiri. Siapa yang menulis di page tersebut?, adakah nomor kontak atau email dari penulis? Apakah dia berkompeten di dalam menulis bidang ini?.

b) Adakah yang memverifikasi informasi tersebut?. Dalam jurnaljurnal ilmiah biasanya selalu tertera tulisan peer review. Artinya bahwa tulisan yang ada di jurnal tersebut telah di edit atau di review oleh ahlinya.

\section{3) Objektivitas}

Objectivitas di sini lebih melihat tujuan daripada pembuatan situs. Karena situs yang baik tentu akan menjabarkan untuk siapa, membahas apa dan dibuat untuk apa. Menurut Cooke (2001), ada 3 pertanyaan yang dapat digunakan untuk mengidentifikasikan tujuan sebuah sumber informasi, yaitu

a) Pernyataan yang menunjukkan tujuan dari situs itu sendiri. Biasanya situs akan menuliskan langsung bahwa jurnal atau sumber informasi yang ditampilkan ditujukan untuk kalangan tertentu.

b) Pembaca yang dituju oleh informasi tersebut. Merupakan kelanjutan dari poin yang di atas, karena dibuat untuk tujuan tertentu maka audiennya pun untuk kalangan tertentu pula.

c) Bagaimana detail dari isi informasi tersebut?

\section{4) Currency (kekinian)}

Hal yang perlu diperhatikan dalam currency, meliputi;

a) Informasi mengenai kapan dibuat? tanggal, bulan dan tahun dari sumber informasi tersebut. Dalam setiap jurnal ilmiah data-data tanggal seperti ini tercantum dengan jelas sehingga kita bisa mengetahui kapan informasi tersebut di upload.

b) Kapan terakhir di update? Apakah ada dead link-nya? Hal ini untuk mengindentifikasikan 
informasi di dalamnya diperbaharui secara berkala atau tidak, berapa lama pembaharuan konten dilakukan.

Kekinian menjadi pertimbangan yang perlu diperhatikan sebab informasi yang lama akan menjadi tidak berguna lagi, tidak relevan dan cenderung menyesatkan (Cooke, 2001).

\section{5) Coverage (cakupan)}

Coverage di sini lebih melihat ke cara mengulas atau cakupan sebuah informasi, di antaranya

a) Topik. Cakupan topik dijabarkan secara obyektif karena didukung data-data yang akurat dan reliable, tidak bias.

b) Adakah link yang terhubung dengan situs-situs lain yang dapat dipercaya untuk mendukung informasi tersebut. Ada beberapa sumber informasi yang menyertakan link ke situs-situs yang berhubungan dengan kontennya, hal ini digunakan untuk memperkuat argumentasi dari apa yang diulas tersebut, disisi lain bisa dikatakan sebagai indikator penelitian sekarang merupakan kelanjutan dari penelitian sebelumnya.

c) Kedalaman dalam menganalisis topik yang disajikan.

6) Gaya penulisan

Menurut Azwar (2011) gaya penulisan termasuk salah satu indikator yang diperlukan untuk mengevaluasi sebuah web. Seorang penulis yang tidak akurat dalam menuliskan ejaan, penggunaan tanda baca maupun kaidah bahasa umumnya kurang memiliki kredibilitas dalam menyampaikan informasi. Hal ini sejalan dengan pendapat Doyle (2006) bahwa kecerobohan dalam memilih bahasa dan gaya penulisan bisa menjadikan sebuah situs tidak bisa diandalkan.

\section{KESIMPULAN DAN SARAN}

Perkembangan teknologi informasi begitu pesat dan beragam, maka sudah selayaknya seorang pustakawan sebagai pekerja informasi dituntut memiliki kemampuan atau kompetensi diri dalam mengkases dan mengidentifikasi sumbersumber informasi mana yang valid, reliable dan akurat sesuai kebutuhan pemustaka.

Saran-saran yang dapat diberikan kepada para pustakawan yakni;

1) Mengadakan workshop, training dan sejenisnya mengenai digital literasi,

2) Dalam kurikulum pendidikan perpustakaan, digital literasi bisa menjadi subjek tersendiri dalam mata pelajaran mengingat pesatnya perkembangan teknologi tersebut saat ini.

\section{DAFTAR PUSTAKA}

Azwar, M. (2011). "Kemampuan Mahasiswa dalam Menelusuri dan Mengevaluasi Informasi Berbasis Internet: Studi Kasus Mahasiswa JIP UIN Syarif Hidayatullah". Jakarta Angkatan 2007. Tesis. Depok: FIB UI.

Baskoro, D. G. B. (2010). "Web Evaluation". Workshop Literasi Informasi untuk Trainer, 21-22 April 2010. Tangerang: Johannes Oentoro Library.

Cooke, A. (2001). A Guide to Finding Quality Information on the Internet : 
Selection and Evaluation

Strategies. London: Facet.

Dalhousie University. "6 Criteria for Websites". Diunduh dari https:/ /cdn.dal.ca/content/dam/ dalhousie/pdf/library/CoreSkills/ 6_Criteria_for_Websites.pdf pada tanggal 19 September 2017.

Doyle, T dan Hammond, J. L. “Net Cred: Evaluating the Internet As a Research Source: Reference Services Review". 34 (1), 56-70, http://doi.org/10.1108/009073206 10648761

Gilster, P. (1997). Digital Literacy. New York: Wiley.

Kent Satate University. "Criteria for Evaluating Web Resources". Diunduh dari http:/ / www.library.kent.edu/crite ria-evaluating-web-resources pada tanggal 12 September 2017.

Pendit, P. L. (2008). Perpustakaan Digital dari A sampai Z. Jakarta: Cita Karyakarsa Mandiri.

Purwono. (2008). "Strategi Penelusuran Informasi melalui Internet". Makalah Seminar HMJ Ilmu Perpustakaan, Fakultas Adab dan Humaniora, UIN Jakarta, 30 April 2008.

Sudarsono, B. (2006). Antologi Kepustakawanan Indonesia. Jakarta: Sagung Seto.

Sulistyo-Basuki. (2013). "Literasi Informasi dan Literasi Digital". Diunduh dari https:// sulistyobasuki.wordpress.c om/2013/03/25/literasi-informasidan-literasi-digital/ pada tanggal 29 September 2017. 